\title{
Preface of Minisymposium "Fourth Symposium on Mathematical Modelling of Hydrological Sciences”
}

\author{
F. Napolitano ${ }^{1}$ and F. Russo ${ }^{1, a}$ \\ ${ }^{1}$ Sapienza Università di Roma, Dipartimento di Ingegneria Civile, Edile e Ambientale, DICEA
}

a) Corresponding author: fabio.russo@uniroma1.it, francesco.napolitano@uniroma1.it

\begin{abstract}
The challenges that poses the hydrological sciences require a lot of efforts, especially in the development and improvement of mathematical models. The need to understand deeply the phenomena puts us in the condition of create models that are more accurate, but at the same time increase their simplicity and reliability. It is therefore important to be provided with high-quality data, whether observed or simulated samples through appropriate software. Statistical models are a constant in all the works of this symposium, which are needed to verify the reliability of empirical literature expression, to predict floods, rainfalls and important economic quantities and to identify the main influencing factors of pluviometric regimes. In this Minisymposium all these problems are faced with original solutions, to contribute the development of hydrology on science pathway.

Predicting the magnitude of flood peaks is the main focus of Neri et al. [1], who use a regional flood frequency analysis based on a Region of Influence approach to estimate the relationship between flood peaks and return period considering annual maximum peak records of 26 water basins in central Italy.

The main aim of Bertini et al. [2] is to detect the dominant directions of synchronized heavy daily rainfall events, applying complex network theory to 15 rain gauges located in Lazio region (central Italy).

The authors in Mineo et al. [3] investigate the influence of the return period (Tr) on Areal reduction factor (ARF) estimation, for heavy rainfall events observed in the Lazio Region (Italy)

Mineo et al. [4] evaluate, among the Kinetic energy - Intensity expressions (KE-I) proposed in literature, which one fits in the best way KE values calculated from potential erosive events collected by a disdrometer installed in Rome (Italy)

Astrologo et al. [5] investigate the feasibility of single thresholds for the classification of daily precipitation in Lazio region (central Italy) using a probabilistic approach.

Duangdai and Likasiri [6] propose a mathematical model to predict agricultural and manufacturing gross domestic product of Northern Thailand using population, rainfall and dams' inflow and outflow time series as predictors.
\end{abstract}

\section{REFERENCES}

[1] Neri A., Sarcinella M., Regional Flood Frequency Analysis With a Region of Influence Approach: Case Study of Pescara River Basin, International conference of numerical analysis and applied mathematics 2018, AIP Conference Proceedings, American Institute of Physics.

[2] Bertini C., Mineo C., Moccia B., Setting a Methodology to Detect Main Directions of Synchronous Heavy Daily Rainfall Events for Lazio Region Using Complex Networks, International conference of numerical analysis and applied mathematics 2018, AIP Conference Proceedings, American Institute of Physics.

[3] Mineo C., Ridolfi E., Neri A., Russo F., Areal reduction factor: the effect of the return period, International conference of numerical analysis and applied mathematics 2018, AIP Conference Proceedings, American Institute of Physics.

[4] Mineo C., Ridolfi E., Bertini C., Napolitano F., Kinetic energy and rainfall intensity relationships: a review, International conference of numerical analysis and applied mathematics 2018, AIP Conference Proceedings, American Institute of Physics.

[5] Astrologo F., Bertini C., Mineo C., Moccia B., Neri A., Magnaldi S., On the feasibility of single thresholds for the classification of daily precipitation in Lazio region, International conference of numerical analysis and applied mathematics 2018, AIP Conference Proceedings, American Institute of Physics.

[6] Duangdai E. and Likasiri C., Gross Domestic Product Predictions Based on Population, Rainfall, Water Inflow and Water Outflow: A Northern Thailand Model, International conference of numerical analysis and applied mathematics 2018, AIP Conference Proceedings, American Institute of Physics. 